\title{
Creativity and Innovation to Improve Processes in a Textile Industry
}

\author{
I. C.R. ALVES ${ }^{1}$, J.H.F.S. SOUSA ${ }^{2}$ \\ 1University of Debrecen, Faculty of Engineering, caiquealves.eng@gmail.com \\ 2University of Debrecen, Faculty of Engineering, jjsousa6@gmail.com
}

Abstract

In this scientific work, the My Creative Idea (MIC) program was created and developed in the Coteminas S.A. textile industry, distributed among the organization's units in the country with emphasis on the São Gonçalo do Amarante unit in the state of Rio Grande do Norte. The aim was to critically analyze the improvements of industrial-scale processes resulting from the creativity and innovation intrinsically incorporated and experienced daily in the program. Thus, the general objective of the work was to evaluate the improvements in the productive processes coming from an innovation program in a textile industry, considering as specific propositions with respect to calculating the gains with reduction of losses, cost of implementation of ideas and measure financial returns and evaluate employee satisfaction according to the program. Moreover, there was free access in the company to be able to collect valuable information that could formalize a robust database for later structuring of the document, as well as the application of action research in the form of questionnaires. Therefore, the results verified clarified and emphasized the program's aggregating character to the organization in a general way under aspects that approach the financial spheres, and the satisfaction and motivation of the employees involved in this whole scenario. I suggest continuing to work on a continuous improvement methodology to further enhance My Creative Idea over the years, as well as insert this method of work to units that have not incorporated this program into their business strategies.

Keywords: My creative Idea. Textile Industry. Program. Process. Continuos Improvement.

\section{Introduction}

Innovation then emerges as a strategic resource for problem solving and continuous improvement programs. Innovation and creativity go hand in hand to try to explore and extract such skills from the people who make up the workforce of an industrial unit integrating, uniting and developing labor practices with ideas that promote fundamental improvements to the organization as a whole.

In this sense, the real impact of a program of creative ideas on the management of the day-to-day routine was evaluated since there are process gains in practice from the validation and execution of an idea, but to evaluate the extent to which this method motivates and makes employees sensitive to feel essential and integral part of the company is a challenge of great value.

In this environment it is essential to observe and analyze the satisfaction of a collaborator towards others, in relation to feeling recognized through awards on behalf of the company. The level of 
involvement and responsibility for your position in the organization tends to grow as your level of trust in the process grows in direct proportion. Feeling useful and important at work, above all, dignifies man and provides a sense of pleasure and well-being. There is talk of a recognition for an idea that will make a difference in a process, an operation, an activity, the minimization of waste and rework, gain of lead time, financial economy, job security, ergonomics. The development of the operational authority stimulated by the program are impactful, integrative, and highly motivating.

Moreover, an important subject to which it is interesting to be evidenced are the formations of the Kaizen groups. From the opportunity to have an approved idea, each person invites other people with a maximum of 5 members to form groups of continuous improvement that must make up the workforce directed to execute the idea. The maximum number of 5 participants per group has been defined by the internal committee to which it governs and controls the premises of the "My Creative Idea" program since its origin in 2016 through the company Coteminas S.A. located in Brazil.

It is understood that 5 is a good number to promote interaction and minimize idle people between groups, considering this line of reasoning for many employees in a single group since a number less than 5 would also result in a few people per group and, thus, a high volume in the number of existing groups. Therefore, for monitoring and control purposes would not be feasible.

The cycle is composed of steps, as can be seen and follows in more detail throughout this scientific work. Creativity and innovation programs are true business drivers in the places where they are present and are responsible for numerous successful cases in Brazil and worldwide.

From the internal initiative of the management command of Coteminas S.A. based in Blumenau, Santa Catarina, the "My Creative Idea" program originated in the second half of 2016. Its emergence occurred through the initiative of a group of professionals who saw a good market opportunity to bet on creative and innovation aspects based on benchmarketing with other companies.

The opportunity aims to take advantage of the intrinsic potential inherent in the manufacturing universe. The reality of the industry occurs through a high level of dynamism and interactions. Every minute there are many machines operating simultaneously, operators are multipurpose, promote a series of movements every instant.

Through this work dynamics, there is a critical view of the observer as an active agent of the organization to whom, through the routine of day-to-day work, it achieves better than other professionals most of the time, observing points to improve due to the knowledge of the process acquired by that certain individual.

In this sense, with the power of knowledge, employees involved in the operational sector feel safe to give their opinion and affirm that a certain change in a part of the machine, an adaptation, a flow optimization, a process improvement, are decisive and feasible to suggest, approve and implement.

My Creative Idea, the result of corporate endomarketing, from the initial start, still crawling, the results quickly appeared precisely based on an exponential growth in number of ideas to be analyzed, month after month.

The management of the phases of the cycle at all times are reviewed and monitored, always seeking excellence in management after all we are dealing with continuous improvement at all times and in this 
sense, the tools of Industrial Engineering are useful and viable, the PDCA cycle can be identified as a fundamental alternative to conduct operational and managerial best practices.

\section{Literature Review}

\subsection{Innovation to improve processes}

Little is known about the effects of lean manufacturing practices on the process innovation performance of manufacturing organisations. This research aims to fill this gap and explore the aforementioned interdependency. The findings suggest that both technical and human lean practices have a moderate to strong positive impact on the input and occurrence of incremental and radical process innovation in manufacturing organisations. In turn, as an output of process innovation, this appears to enhance companies' operational performance. [1]

Companies of different size and segments are being forced to seek new means of management according to the changes that have been taking place such as globalization, advancement of Information and Communication Technology, increased customer demand and competitiveness. [2]

In this environment, it is important to understand that there is a need to reinvent competitive advantages, so sectors with low intensity in technology and knowledge lose space and economic participation. Therefore, the challenge of producing more and better is being replaced by the continuous challenge of innovating processes, products, services and management systems. [3]

According to Borchardt and Santos (2014), innovation consists of a process that integrates the organization in general. It is configured as the kick-off to achieve a competitive advantage and for this, well-structured decisions are needed by senior management and effective resources that can reflect priority with regard to innovation; conducting processes and tools tailored to innovation management, exercised by operational areas involved; to ensure the ability to exploit their resources with organization and social responsibility, as well as encompass efficient project management; in addition to the ability to undertake and promote leadership with authority at the technical and managerial levels. [4]

The main purpose of strategic innovation management is to seek to promote a structural form to, through a strategic perspective, that is, whose ultimate objective is to achieve sustainable competitive advantage, structure routines; tools; processes, capabilities; standard resources and procedures in a systemic manner. Starting from these principles via coordinated actions, the interest is to provide innovation with a certain periodicity, systematization, discipline, and not simply something spontaneous or even accidental. [4]

However, there are no formulas ready to create something innovative or to manage the process. Each company has its intrinsic particularity and, thus, distinct demands, seeking to align them with its strategy, its activity sector, physical structure, positioning, in addition to capabilities and resources. Therefore, organizations tend to customize the management of innovative processes according to their interests and priorities since certain specificities restrict management options. [5] 
State-of-the-art organizations invest in the power of innovation and technological development through incentives such as awards, competitions and seminars to develop innovative projects. Innovation is undoubtedly recognized as a key and fundamental factor for the development of companies and, especially, for the country. It is possible to achieve this in an increasing collection for more innovative projects. [6]

Thus, even if sometimes confused, the management of innovation and creativity are not the same process. In a variety of ways, creativity management deals more with the subjective aspects involved in innovation, exemplified as the process of creating the idea by the talents of the organization, climate management of the team or organization, emotional intelligence, creative leadership styles, values assumed by the participants of the process, among other elements. While innovation management refers better to the "hard" aspects or expected results that are estimated by the team and the organization. [6]

Both processes mentioned, the management of creativity and innovation management must go in parallel and fully integrated. However, this usually does not happen since, depending on the basic formation of managers, there is a tendency to prioritize one process or another and due to the daily pressure inherent to the process, the predominant influence is to prioritize innovation management. [6] The interest of the search for innovation has risks and the process of innovation is loaded with uncertainties, with many variables, including technology and its approaches, the nature of competition, the market context where it will be launched as well as the political-social context. Innovation Management itself aims to help minimize these risks, keep over control the resources allocated to the process and provide more value over the technological result and innovation itself, when introduced to the market. [7]

\subsection{Creativity}

According to Florida (2011), the economic scenario, creativity is a widespread concept and occurs continuously since we are continuously analyzing and improving products, processes and what concerns activities, integrating them in new formats. [8]

According to Florida (2011), "The driving force is the rise of human creativity as a central agent in the economy and in life in society. Whether at work or in other spheres of life, we never value creativity so much and never cultivates it with such commitment. The creative impetus - the characteristic that sets us apart from other species - is being unleashed on an unprecedented scale." [8]

Florida (2011) comments that "creativity must be promoted in various ways by employers, by creative individuals themselves and by the communities where they live. It is not surprising that the creative ethos transposes the world of work and penetrates all spheres of life." [8]

According to Florida (2011) "We jump from job to job without effort or great concern. If before people joined through social institutions and forged their identity in groups, one of the main characteristics of today is related to the effort to find an identity of their own. This invention and reinvention of the $i$, which usually reflects our creativity, is the main feature of creative ethos." [8]

Basadur and Basadur (2012) Sousa et. al. (2015) , with regard to the business scenario, the posture of actions with direction of creativity are passive adaptations to the environment, since they represent the 
International Journal of Engineering and Management Sciences (IJEMS) Vol. 6. (2021). No. 3

DOI: 10.21791/IJEMS.2021.3.7.

search for unique strategies, with added value to which it can reinvent a current scenario, promoting a line of promotional reasoning for innovative practices. Innovation is a factor of competitive advantage in companies in general. In the industrial sector, the emphasis on productivity $\mathrm{x}$ cost is fundamental, the great purpose is to make money, making the production process act with quality with the lowest lead time and waste, that is, less rework possible. [9]

\section{Materials and Methods}

\subsection{Materials}

Nowadays, the program is recognized nationally since it is replicated in 6 other units of Coteminas S.A. in the national scenario, located in Montes Claros (MG), Blumenau (SC), João Pessoa (PB), Campina Grande (PB), Macaíba (RN) and São Gonçalo do Amarante (RN).

On the inside as well as externally the company this management model serves as a successful case in benchmarketing for several other organizations in the industrial segment. Thus, this practice is increasingly disseminated and practice.

From the ongoing success, manufacturing directors had the idea of expanding the activities of My Creative Idea through the implementation of a Nude Exhibition of Ideas that could integrate the company's national units together in the same environment, a kind of endomarketing with a lot of integration involved.

Priori participations would be restricted only to the units of Blumenau (SC), Rio Grande do Norte (RN) and Campina Grande (PB). This event has as its main purpose to integrate and involve employees in a competition format to which it demands commitment, however executed in a healthy way.

With regard to the subject addressed, for example in the state of Rio Grande do Norte there are two units of the corporation, located in Macaíba (MCB) and São Gonçalo do Amarante (SGA). In this sense, annually both make the state confrontation of the best ideas processed of that respective year. And in the end, there were cash prizes for ideas classified with financial return for the company, and awards in products of Coteminas S.A. for ideas without financial return.

The meaning of the classifications of ideas stands out. In 2017, MCB and SGA participated in the Exhibition Annual de ideas promoted by the company's internal management committee, a true science fair with several ideas executed in the units themselves throughout that respective year. The target audience is the other managers of the units as well as employees from other cities, managers and industrial directors.

The possible categories of competing are two: ideas with financial return (green record) and ideas without financial return to the organization (yellow record). Both categories to be able to be shown in the event must necessarily have been run by the date of 1 month before the day of the event.

To participate in the green records, the groups needed beyond the execution of the idea as already said, to perform cost analysis through data collection on what changed in relation to reality before and after the implementation of the idea, and finally structure and edit slides that can help to evidence what was done and what brought improvement in the before-after confrontation. It is worth noting that each idea 
had only 5 to 10 minutes for exhibition and explanation on the meme, taught by only one person representing each group.

The participation in the green card provides the group with the winning idea of the category, a cash prize. In this case, there are three possibilities of gain with different values.

First, the highest place on the podium took home $\mathrm{R} \$ 500,00$ per person participating in the group. The second place won $\mathrm{R} \$ 400,00$ each and the third $\mathrm{R} \$ 300,00$ each component.

In addition, there are also yellow chips. The category of yellow chips has its particularity in relation to green ones. These do not compete for cash prizes but products from Coteminas S.A. itself.

In this sense, the yellow category has a slightly lower weight compared to the green ones due to the final result of its benefit. Those ideas that consist of ideas without financial return to the company compete to the company, ranging from a process gain, optimization of a flow, better compliance with the standards of work safety and ergonomics of the employee.

Therefore, the motivating character of the II Annual Projects Exhibitions notorious, an event that occurs once a year since it can provide a significant increase in income. In addition to motivation, promotes healthy integration in the organization in general, there is a tendency for My Creative Idea to grow over the years.

The emphasis of the proposal of this annual competition is directed to ideas of success since they exist. The examples that exceed the value of $\mathrm{R} \$ 100,000.00$ annually, according to company's calculations.

In view of the considerations, the problem of this work can be formulated through the following question: how does the program "My Creative Idea" contribute to the improvement of the quality of products, cost and to the satisfaction of employees in a textile industry?

\subsection{Method}

According to Turrioni and Melo (2012), regarding the classification, this research fits with applied since real data were generated to be delivered and practical problems solved. The objectives of the research are exploratory and descriptive because it explores the fact and describes it, the procedure being applied will be the documental visa that documented business data in the field, that is, in loco. [10]

The nature of the proposed research was qualitative precisely because it emphasizes the importance of the quality of information and to define the target audience to be collected as a sample, as well as the quantitative nature seeking to really measure the results and measuring efficient training to be the most representative possible.

Regarding the research method approached, among the possible options that best fit the work profile was the action research through the application of questionnaires.

Finally, the work was carried out in the field and in this case, the author who must adapt to the environment, conducting the routine of day-to-day in a dynamic and practical way aiming to apply the theory absorbed in the classroom in the real experience of the manufacturing universe.

Through availability through Coteminas S.A. company, it was possible to have access to the database necessary to work on information and communication management, thus allowing to collect data with 
quality and extract from these a careful analysis that favors the learning process and construction of the ideal line of reasoning for the composition of scientific work.

A priori, action research was planned through the conceptual structure and selection of the area of analysis, precisely the unit of São Gonçalo do Amarante itself. Then, it was necessary to collect data through the application of on-site questionnaires and informal conversations on the subject. The next step was to analyze the data and start planning actions to organize the decisions that would be made, so an action plan was prepared. Finally, the actions were implemented, and the data compiled in tables in an integrated way, so it was possible to verify the results and make the correct reading of what the data transmitted.

The evaluation of the values were based on historical data, the purpose is to compare the gains after the beginning of the program in 2016 and in this sense, to measure the gain that the company had in this interval of one year until August 2017. Among the ideas in focus, which have the most varied return values, there are some one-off actions that exceed the value of $R \$ 100,000.00$ annually each, and together, accumulate gains of almost $\mathrm{R} \$ 900,000.00$ per year.

Moreover, not least, it was related to the focus directed to the motivation and satisfaction of employees in the face of participation and involvement with the factory routine program. Recognition as an active agent of the organization through awards is difficult to measure, a great level of abstraction, really was a challenge to evaluate on a solid basis what the whole scenario provides to the individual.

It is also essential to mention the participation of these people in kaizen groups of mutual help, Coteminas Continuous Improvement Groups (GmeCC) through mic, bringing collaborative feeling to participants and quite integralizing. From the integralization arises the constant desire to suggest new ideas and this in a result, continuously reflects the motivating character of the program.

Moreover, the awards in products produced by these same employees, from their receipts can be marketed externally to the organization in a lawful and valid way. This benefit still helps mostly humble people, supplement their monthly income and directly increase their interest in participating. The benefit cited, dignifies and adds value to both the individual and Coteminas S.A., not to mention the increase in the sense of urgency in executing the ideas and in this sense, increasingly faster receive the awards and repeat the cycle again.

\subsubsection{Stages of the research}

The research had about 22 fronts of scope between statements and questions, divided between two distinct views regarding the theme of conditions for creativity and satisfaction of the work environment, first were the favorable conditions for creativity and secondly the scale of satisfaction with work.

In this sense, the elaboration methodology was made structuring these questions in two blocks, two moments. The first of them with 12 questions, and the second with 10.

For each question there was a blank space in parentheses on the same line as the respective question to which it should be filled individually from a legend with five answer options. The correct method was to answer only one number as an answer to each of the statements and/or questions. 
From the caption contained in the survey (1- I do not agree, 2- I do not partially agree, 3- I am not able to give an opinion, 4- I partially agree and 5- I totally agree), the people involved answered this number according to their perspectives in relation to the My Creative Idea program, considering that it was not necessary to insert names on paper or any other personal record, therefore, this strategy was used in order to be as representative as possible in the collection and evaluation of opinions.

\subsubsection{Questionnaire}

The research was based on a series of closed questions in order to concretely measure the impression of Coteminas S.A.'s collaborating professionals in the face of the reality that they are directly interconnected.

In this sense, it was possible to observe factors that may tend to positively influence the organizational development of companies with emphasis on creativity and innovation applied to industrial daily life.

Questionnaire form

\section{A - Relationship between conditions for creativity and job satisfaction}

- Working Conditions Indicators (ICCAT)

- Favorable Conditions for Creativity (ECFC);

- $\quad$ Selected questions

1. Freedom to expose ideas

2. Freedom to propose new ways of doing the activities

3. Freedom to express ideas different from other

4. The organization has in its guidelines the search for creativity

5. Access to information favors the emergence of new ideas

6. Interaction with colleagues encourages the production of ideas

7. Colleagues encourage suggestions

8. Colleagues praise a good idea

9. Manager encourages in the search for unique solutions

10. The manager encourages suggestions to improve services

11. The manager encourages participation in the solution of problems

12. Task difficulties stimulate new ideas

- Reduced version of the Job Satisfaction Scale (EST)

- Work satisfaction scale

- $\quad$ Selected questions

1. There is confidence in co-workers

2. The spirit of collaboration of co-workers

3. The way to deal with the boss

4. The absorption capacity of the work

5. The degree of interest in the tasks

6. How much does the MIC program help in the income?

7. How much the MIC program motivates and stimulates the generation of new ideas 
8. Did the MIC program make the company better in your vision after its implementation?

9. Do you consider that the MIC program is evolving in relation to its creation in 2016 ?

10. Feeling of satisfaction about the existence of the program

The research was elaborated on a computer, then printed and applied to the target population, a selected sample of authorized employees who are able to respond, that is, people who are part of My Creative Idea. It is worth considering that names or personal records of people needed to be identified, justifying an approach that allowed higher levels of veracity of the information collected.

The action research had a variation of the original proposal of Boas (2015), Roque (2008) and Santos (2014), from a scale of five points, whose range of response varied the values from 1 to 5 (I totally agree not to agree), in a total of 22 questions. The response period was 3 days, from 12/09/2018 to $14 / 09 / 2018$, then the data were analyzed according to qualitative method. [11]

\subsubsection{Describe the population and sample}

The characteristics of the unit under analysis are a textile production industry covering areas of Yarn, Fabric, Processing and Clothing. The work was carried out more specifically in Processing, in which it is subdivided contemplating the sectors of Preparation, Stamping, Dyeing, Finishing and Inspection. The work dynamics and monitoring of process flows are based on pulled production, that is, the well-known lean production based on just in time, custom production in which production is only started from the previous existence of a demand.

The company works with minimal batches to be produced, with short lead times and high flexibility of procedures. Cost accounting apportionment methods use "meter" as the base unit and as filter parameters in cost centers to therefore appropriate them via apportionment criteria identified as manhour rate in sectoral production orders.

\subsubsection{Describing the flow of ideas}

In the first stage the collaborator suggests an idea and this idea will go through an evaluating bank (1st stage). If approved, the individual will be awarded in the event My Creative Idea monthly and, this idea will have the right to move to the next phase, the creation of a group of up to 5 components and 1 sponsor with the objective of executing the suggested idea (2nd stage).

The sponsor is a collaborator to whom he must exercise the position of supervision and in this sense, will have the mission of guiding the group or the groups to which they are under his supervision and with them to perform well in their activities in general.

After the idea executed, unlike the first award that is individual, all components of the group are awarded as well as the godfather in the same way and, therefore, is given low in the system with the registration of the idea in an internal database. 


\section{Results and Discussion}

\subsection{General Analysis}

From the analyses presented and the problem developed, the general objective and the specific objective scans of the present work are exposed.

The overall objective of the work is to evaluate the improvements in production processes and people from an innovation program in a textile industry.

\subsection{Specifics}

- Calculate gains by reducing losses and measure financial returns;

- Assess employee satisfaction according to the program.

\subsection{Contextualization}

Table 1 represents in a contextualized way the objectives outlined for the elaboration of this scientific work. Regarding the subject addressed, it is essential to direct goals and sub-goals as a way of guideline and route in the progress of routine actions. This strategy was very important to clearly see what the work proposed to do and execute, in addition to its purpose.

Table 1: Contextualized objectives.

\begin{tabular}{|c|c|}
\hline \multicolumn{2}{|c|}{ OBJECTIVES } \\
\hline $\begin{array}{l}\text { General: Evaluate the improvements in production processes } \\
\text { and people from an innovation program in a textile industry. }\end{array}$ \\
\hline \multicolumn{2}{|c|}{ Specific } \\
$\begin{array}{l}\text { Calculate gains with loss } \\
\text { reduction and financial return }\end{array}$ & $\begin{array}{l}\text { Assess employee motivation } \\
\text { based on the program }\end{array}$ \\
\hline $\begin{array}{l}\text { Measure real return } \\
\text { values for the } \\
\text { company based on } \\
\text { historical data } \\
\text { (compare with values }\end{array}$ & $\bullet \begin{array}{l}\text { Recognition as an } \\
\text { active agent in the } \\
\text { organization } \\
\text { Participation of } \\
\text { mutual aid groups }\end{array}$ \\
\hline
\end{tabular}




\begin{tabular}{|l|ll|}
\hline after the program & & (kaizen) \\
started) & $\bullet$ & Encouraging \\
creativity and \\
Emphasis on & & innovation \\
successful ideas with & Constant motivation \\
financial returns & to suggest ideas \\
\hline
\end{tabular}

Source: Own Elaboration (2021).

Regarding the paths that have been designed to achieve the objectives there are actions that have been carried out, these are the cases of the specific objectives as seen in Chart 1.

Thus, these actions are only the most superficial layer of the proposed analysis, this theme leads us to a diversity of areas such as possibility of scope and interests.

In this sense, a critical study was carried out on the implementation of ideas that produce financial return to the company, however it is a fact that there are also ideas that do not provide such gain but include other topics of great value and relevance such as process improvement, the minimization of a flow, better adaptation to safety standards by operators, among other opportunities for improvement.

\subsection{Describing the characteristics of the units of analysis}

According to data collected until 28/06/2017, the program after its creation in August 2016, involved about 160 employees, not including in the staff count, distributed in 32 Kaizen groups totaled a cumulative of 140 ideas approved in the Unit of Macaíba and 289 ideas of the unit of São Gonçalo do Amarante, totalling 429 approvals as detailed in the Quadro 2.

Table 2: Data from the My Creative Idea program.

\begin{tabular}{|c|c|}
\hline \multicolumn{2}{|c|}{ MIC - COTEMINAS RN } \\
\hline São Gonçalo do Amarante (SGA) & 289 \\
\hline Macaíba (MCB) & 140 \\
\hline Employees involved & 160 \\
\hline Total of groups (GmeCC) & 32 \\
\hline Executed ideas (SGA + MCB) & 80 \\
\hline Total of ideias in Rio Grande do Norte (RN) & 429 \\
\hline
\end{tabular}

Source: Coteminas S.A, (2018).

From Table 2, it is possible to observe that 80 ideas were executed. Therefore, there was a need to minimize the difference between ideas approved and executed, in this sense, it was proposed to the author to pursue this challenge in the position of catalyst agent, cooperating and being part of the program's guiding team, being directed to the unit of São Gonçalo do Amarante. 
Through data collected until 14/05/2018, the program has grown exponentially since its creation in August 2016, which today includes about 240 employees, not including the staff count, distributed in 56 Groups GMeCC (Continuous Improvement Groups Coteminas), totalling an overall accumulated of 1,608 ideas suggested considering the units of Macaíba and São Gonçalo do Amarante together.

Regarding the analysis of each unit, São Gonçalo do Amarante (SGA) leads the ranking of ideas to be analyzed by the evaluator bank since it has an amount of 1,112 ideas. On the other hand, Macaíba (MCB) accumulates 496 suggestions.

In this sense, among the 1,608 to analyze, 694 were approved after analysis through the company's evaluator banking, to the detriment of 709 disapproved ideas. Regarding the overall number of ideas, 54 have been identified as claims and are included in the distastes. The claims need to be understood as actions that are contrary to the concept of the My Creative Idea program, or are ideas with an interest to claim something that is not necessarily pointed out as an idea or is for the benefit of the organization. In addition, 116 ideas have been identified as repeated, that is, they are automatically disproved, another 35 ideas are pending analysis as staff scored.

Therefore, it is evident the growth of the program considering this scenario after about 1 year. The number of ideas executed, the mic's greatest emphasis, rose to 292, a significant jump after a short time in terms of proportionality. Therefore, a more detailed analysis is important to illustrate the updated results more accurately as described in Quadro 3.

Table 3: Analysis of the Program My Creative Idea.

\begin{tabular}{|c|c|c|c|}
\hline \multicolumn{3}{|c|}{ MIC COTEMINAS RN - ANALYSIS } \\
\hline VARIABLES & $\mathbf{2 0 1 7}$ & $\mathbf{2 0 1 8}$ & VARIATION \\
\hline $\begin{array}{c}\text { São Gonçalo do Amarante } \\
\text { (SGA) }\end{array}$ & 289 & 1.112 & 823 \\
\hline Macaíba (MCB) & 140 & 496 & 356 \\
\hline Employees involved & 160 & 240 & 80 \\
\hline Total of groups (GmeCC) & 32 & 56 & 24 \\
\hline Approved ideas (SGA + MCB) & 429 & 694 & 212 \\
\hline Executed ideas (SGA + MCB) & 80 & 292 & 1.179 \\
\hline Total of ideias in Rio Grande do & 429 & 1.608 & $23 \%$ \\
\hline Norte (RN) & $19 \%$ & $42 \%$ & \\
\hline
\end{tabular}

Source: Coteminas S.A (2018).

In a sense, according to the data shown in Table 3, the evolution of the variables and their respective values is notifiable. The unit of São Gonçalo do Amarante again was framed as the unit that leads the 
general requirements of the program with an increase of suggestions reaching 823 ideas, while Macaíba also varied positively in 356 new ideas. The number of active teams was another aspect that increasingly solidifies the daily work of the company's support, regarding the increasing representativeness of more employees with an interest in participating. Thus, there was an increase of 24 new groups together with 80 new participants.

Finally, focusing on the relationship between ideas approved and executed considering 2017 and 2018 it is possible to realize that in 2017 the comparison of 80 executions against 429 approvals, represented only 19\% efficiency in the process. However, considering the current outlook in 2018 with 292 executions to 694 approvals, this ratio reaches jumps to an efficiency of $42 \%$, sustaining a brand that only tends to grow even more in line with the success of the program My Creative Idea.

All the data presented below were based on information, from the year 2017, acquired in the internal database of the Coteminas S.A. company.

\subsection{Satisfaction}

The approach to job satisfaction aimed to measure how the employee sees the My Creative Idea program since its origin in 2016, contemplating issues from this beginning to routine activities in their daily life of the factory. From the application of a standard questionnaire, response was collected and organized so that an analysis could be elaborated.

Through answers compiled in the Excel Software, the frequency of answers for each block of questions was determined. The Conditions favorable to creativity and the Work Satisfaction Scale of employees were analyzed.

This research aimed to answer how the professional collaborator visualizes the favorable conditions for creativity and the scale of job satisfaction and thus measure the perception of the workers of Coteminas S.A. After analysing the results, it was concluded that the research reached the objective, since the opinions of the people involved in the daily process of the company were evaluated regarding the propositions of the questionnaires in terms of agreement, disagreement and percentage variation. When analyzing the frequency of responses, in all factors, they are answered mostly as I totally agree.

Therefore, the application of the methodology was able to achieve the desired objectives in which it is to be able to measure and qualify the research with concrete and solid data in view of the information obtained.

\subsection{Cost}

The analysis in this topic addressed the relationship between the cost of implementing some ideas versus the financial return they brought to the company, it can be said that within a broader context it is the best ideas in the list of the My Creative Idea program, the most important and influential, with higher levels of benefit to the organization.

Thus, it is important to highlight that the most active and most influenced sectors of Coteminas S.A. were identified and evaluated, which includes about 2 active participating units of the program spread throughout the country, in this case Macaíba and São Gonçalo do Amarante. 
In this sense, the department highlighted with higher values and benefits among the ideas analyzed as implementation cost and financial return is the Finishing under the responsibility of Mr. Rogério Damião, in a total of 10 ideas mapped with their proper memories of calculations and their respective values. It is also the largest number of ideas executed and with the highest amount of financial return. The ideas detailed below accumulated a total of R 848,405.70 in savings between 2016 and 2017.

Table 3 represents the description of the approved ideas, then executed, that is, implemented in the organization and considered in this sense with higher rates of financial return. The divisions are distributed among numerals, the proposal of suggestion, opportunity appears as a measure of arguing and supporting the proposed suggestion and thus corroborate it. Next, it is important to highlight the benefits to which the company has been provided, as well as each idea necessarily needs to be named to be processed in analysis of the evaluator bank. All groups in the My Creative Idea (MIC) program have fancy names to identify components of the different participating groups more easily.

The sectors have their respective managers responsible for analyzing and interfering in the approval and/or execution of an idea that is part of their flows. Moreover, based on this principle, 10 main ideas identified as superior in emphasis were listed in view of the other existing ones and, therefore, more impactful, and influential.

After discriminating in detail the main ideas of finishing in the unit of São Gonçalo do Amarante under the responsibility of manager Rogério Damião and general supervision of Alexandre Costa, the paths to reach such values exposed in detail in the memory of calculations of this scientific work were evidenced.

Therefore, it is evident after the calculations and analyses made the efficient character of the MIC program, which is positioned in a considerable competitive market advantage. It is interesting this perception since the average annual gain of the company after August 2016 where My Creative Idea had just been born, obtained the amount of $\mathrm{R} \$ 424,202.85$ annually. The values are valid only for these main ideas of the specified sector, notoriously evaluated between 2016 and 2017.

\section{Conclusion}

Organizations constantly seek to achieve competitive advantages and best management practices as integrated and recognized processes, in addition to exploring and interconnecting an intimate relationship between innovation and creativity that could be explored and interconnected here. Moreover, the favorable economic moment of the country with regard to the creation of new strategies that provide value to the organization, the ability to live with adversities and new demands focused on the textile industry with an intense dynamics of processes provided the development of this work.

Other aspects were addressed throughout the work, such as creativity, innovation, process improvement and motivation. The importance of creativity programs and suggestions for improvement for companies representing the strength of knowledge of those who are living the daily life of the manufacturing universe, in which often have access to the best practices of a flow, optimization of a process, gains in times and displacements, among other factors that managers of the highest levels cannot see, or if they do, they don't see it the same way. 
It is essential to highlight the relationships between kaizen groups of continuous improvements, strengthening ties and forming true families in companies. Through individual and collective awards, it was possible to bring into the organizations a feeling of utility, of importance, a feeling that any collaborator there can make a difference.

The present scientific work has achieved the desired and proposed results in the objectives, such as the general objective: to evaluate the improvements in production processes and people from an innovation program in a textile industry. As well as the specific ones: Calculate the gains with the reduction of losses and measure financial returns; identify improvements in relation to product quality; evaluate employee satisfaction according to the program. It also brought high levels of financial return in the form of savings, positive variation in product quality index and employee satisfaction.

The methodology proved to be adequate and satisfactory from the data collected and analyzed, had sufficient capacity to qualitatively measure the analysis of values and in this sense, emphasizing the motivating and integrating character on the part of the company's employees to the My Creative Idea program.

The limitation of the research consisted of the quantitative aspect of exploratory analysis since it was not possible to have access to a sample considered robust with regard to the total number of active participants who could have answered the questionnaires and thus corroborate more to the method of action research imposed.

The MIC program is to share experiences, bring people together and generate creative and innovative solutions that aim to generate results, whether economic, ergonomic, or social. Through the direct participation of managers in this process, it is possible to expedite the approval and implementation of projects, which in this sense contribute directly to the company's continuous improvement system. Feeling an integral and recognized part is priceless! My Creative Idea is a program that contributes to human growth and business success.

In this sense, the programs of creativity and innovation, more than mere hypotheses or unknowns, are framed as differential impacts about competitive market advantages. Companies that can see and identify this internal potential can benefit in an alternative way through this global crisis and, thus, can take better advantage of this opportunity, undoubtedly are seen prominently and position themselves one step ahead of their other competitors.

It is believed that the work is important for the company with regard to the possibility of contributing to the organization as a catalyst agent between approved and executed ideas, as well as having a reference position in coordination, control of execution of ideas and orientation of the program in the unit of São Gonçalo do Amarante.

With regard to society, it is interesting to promote an incentive with regard to creativity and innovation applied to the reality of the manufacturing routine since with more industries adhering to this strategic policy, more stimuli can be propagated and in this sense, it is possible to have an increase in the innovative capacity index in the national scenario. 
In the author's view, it shows the effective monitoring of an aggregating corporate strategy during the internship in the company. I was possible to observe that this work contributes to human growth and was understood to be a great opportunity to share these experiences.

\section{References}

[1] MOLDNER; REYES; KUMAR. Exploring lean manufacturing practices' influence on process innovation performance. Journal of Business Research. V. 106, P. 233-249, Jan 2020.

[2] ARAUJO, J. B.; ABREU JUNIOR, O. F.; ZILBER, S. N. Adoção de E-BUSINESS e geração de inovação. SIMPOI. 2010. Available at:

<http://www.simpoi.fgvsp.br/arquivo/2010/artigos/E2010_T00376_>. Accessed on: 01 May 2018.

[3] VAZ, C. R.; FAGUNDES, A. B.; PINHEIRO, N. A. M. O surgimento da ciência, tecnologia e sociedade (CTS) na educação: uma revisão. I Simpósio Nacional de Ensino de Ciência e Tecnologia -ISBN: 978-85-7014- 048-7, 2009. Available at: < http://150.164.116.248/seer/index.php/ensaio/article/view/21/52>. Accessed on: 13 May 2018. Vilha, A. M., \&Quadros, R. (2012). Gestão da inovação sob a perspectiva do desenvolvimento sustentável: lições das estratégias e práticas na indústria de higiene pessoal, perfumaria e cosméticos. Revista de Administração e Inovação, 9(3), 28-52.

[4] BORCHARDT, Pietra; SANTOS, Glicia Vieira dos. Management of ideas for innovation: transforming creativity into practical solutions. Journal of Administration and Innovation. V. 11, n.1, p. 203 - 237, Jan - Mar, 2014. Available at: <https://www.sciencedirect.com/science/article/pii/S1809203916301413>.

[5] QUADROS, R. (2008). Learning to innovate: technological innovation management standards in Brazilian industrial companies. Campinas: UNICAMP. QUADROS, R.; VILHA, A. M. (2006). Information technologies in the management of the innovation process. Fonte Magazine, 5, 129133. CARVALHO, R.Q., SANTOS, G.V., BARROS, M.C., NETO. (2013). R\&D+ strategic management in a public company in the Brazilian electric sector. Journal of Technology Management \& Innovation, 8(2), 235-250.

[6] CHIBÁS, F. O.; PANTALEÓN, .M.; ROCHA, T. A. MANAGEMENT OF INNOVATION AND CREATIVITY TODAY: APONTES E REFLEXES. HOLOS, v. 3, 2013. Available at: < https://doaj.org/article/639d3498537a48e0b5cfecb066dac8f7>. Exacta, São Paulo, v. 9, n. 1, p. 59-70, 2011.

[7] ANACLETO, C.A.; PALADINI E. P. Proposal of a model for the quality management of organic foods from Garvin's perspective. VI NATIONAL CONGRESS OF EXCELLENCE IN ENERGY MANAGEMENT, Innovation, Technology and Complexity for Sustainable Management. Niterói, RJ, Brazil. 2010. Available at:<http://www.excelenciaemgestao.org/Portals/2/documents/cneg6/anais/>.

[8] FLORIDA, Ricardo. The rise of the creative class. Ed. L\&PM EDITORES. 2011. V. '1. P. 05-07.

[9] SOUSA, Fernando Cardoso; NUNES, Florbela; MONTEIRO, Ilena Sparrow. 2015. Available at: $<$ http://periodicos.ufpb.br/ojs2/index.php/tpa/article/view/24878/14434>.

[10] TURRIONI, Prof. Dr. João Batista; MELLO, Prof. Dr. Carlos Henrique Pereira. 2012. Available at: $<$ http://www.marco.eng.br/adm-organizacao-

I/Apostila Metodologia Completa 2012 \%20UNIFEI.pdf $>$.Accessed on: 24 Nov 2018.

[11] BOAS, E. P.V. The behavior of the entrepreneur and its influences on the creation process and performance of the company. 2015. 149 f. (Thesis in Administration) - Faculty of Economics, Administration and Accounting, University of São Paulo, São Paulo, 2015. ROQUE, L.M. Ability to 
International Journal of Engineering and Management Sciences (IJEMS) Vol. 6. (2021). No. 3

DOI: 10.21791/IJEMS.2021.3.7.

change and entrepreneurial profile as mediators of strategic performance. 2008. $98 \mathrm{f}$. (Dissertation in Business Administration) - Faculty of Business Sciences, FUMEC University, Belo Horizonte, 2008. SANTOS, M. J. Consumer guidance and financial performance: an analysis of the role of product innovation capacity. 2014. $145 \mathrm{f}$. (Thesis in Administration) - Faculty of Administration, Accounting and Economics, Pontifical Catholic University of Rio Grande do Sul, Porto Alegre, 2014. 